\title{
Novel Recycled Brown Paper Coatings
}

\author{
H. M. El-Sherif, A. M. Nasser", A.I. Hussin", H. Abd El- \\ Wahab", M.B.M. Ghazy" and A.E. Elsayed \\ Polymers \& Pigments Department, National Research Center \\ and ${ }^{*}$ Chemistry Department, Faculty of Science, Al-Azhar \\ University, Cairo, Egypt.
}

\begin{abstract}
CURRENTLY, styrene acrylate copolymers have highly been employed in paper coating application. In sequence to contribute to the green environment approach, different styrene acrylate copolymers with different pigment percentages were formulated and applied on recycled brown base paper in order to determine the most efficient coating. The study also investigated the applicability of Egyptian ground calcium carbonates in paper coating as an alternative of the traditional imported kaolin pigment. The effect of such binders on mechanical properties; water absorbency "Cobb60"; air permeability of paper; gloss and printability of coated paper was explored. The water absorption of coated papers was $30 \mathrm{gm} / \mathrm{m}^{2}$ compared with $35 \mathrm{gm} / \mathrm{m}^{2}$ for the commercial one. This means that ink consumption can be decreased by $\approx 30 \%$ in concert with the possibility of usage of low viscous ink. Gloss of coated papers was upgraded to more than double that of base ones. The burst strength; ring crush and the tensile strength for the coated papers were simultaneously improved compared with the commercial ones. The printability of coated papers was as well superior to the commercial one; this can evidently reduce the economical cost of the printing process.
\end{abstract}

Keywords: Recycled brown base paper, Paper coating, Styrene acrylate binders, Packaging, Printability, Offset printing.

Paper substrates are widely used in packaging due to their high strength, flexibility, low cost and recyclability. Surface coating is one of the most common methods to improve optical properties and surface uniformity of paper as it regulates both ink absorption and distribution on paper ${ }^{(1,2)}$. Conventionally, paper is coated with various types of pigments such as kaolin, calcium carbonate, titanium oxide, etc. Binders such as styrene butadiene rubber, styrene acrylate emulsion and poly vinyl acetate were also utilized.

Porosity and surface roughness of substrate are of primary significance for the quality of coated paper. There are many factors which influence roughness and porosity of coated paper, namely, presence of fines, coarseness of fibers,

\footnotetext{
\# Author for correspondence: IsmaelAhmed1@yahoo.com
} 
ratio of soft wood to hard wood, fiber size and size distribution, filler content effect, formation, and so on ${ }^{(3)}$.

The porosity of the sheet is the ratio of pore volume to total volume and it greatly affected many properties such as hardness compressibility, resiliency and the ability to absorb inks. The permeability is an indicator that shows how printing inks will penetrate and spread.

It was reported that many properties of coated paper can be improved by optimizing coating pore structure ${ }^{(4)}$. Recently, it was concluded ${ }^{(5)}$ that the pore volume in the top-coating determines the spreading of the micrometer silver ink and coat air permeability is based exponentially on surface porosity. Furthermore, the porosity distribution and surface roughness can mainly influence paper-printing ink interactions ${ }^{(4)}$.

The constancy of the printed image is a very vital measure for quality issue. The approval of coated paper by printers is mainly based on its run-ability in the printing process and its printability with respect to defects-free image. The printability of paper is predominantly valuated by the surface of the coating, and its chemical structure and topology distribution ${ }^{(6)}$.

Printing parameters can be assessed by measuring optical, colorimetric and mechanical properties. Printability is the consequence of interactions between paper and both the printing ink and printing press ${ }^{(7)}$.

Oil-based inks, as in our work, compared to water-based inks, does not lead to a great harmful distortion on the paper surface and do not make a hazard for health and the environment compared with solvent-based ones. The basic mechanisms, control ink behavior on paper surfaces, are specifically, penetration, fluid evaporation and swelling ${ }^{(8)}$.

As far as the printing process is concerned, offset printing is more common. Offset printing necessitates a particularly well bound coat due to significant forces in the z-direction exerted by means of the highly viscous inks at the high printing speeds of today. To satisfy these strength demands, large amount of binder is essential. At the same time, the coating must be porous enough to allow fast, controlled absorption of the printing ink keeping the print gloss intact. In general, the coated paper must have acceptable stiffness, resistance to blistering, good dimensional stability, high brightness, no or low yellowing tendency, and good aging resistance ${ }^{(9)}$.

This study aimed at preparation and characterization of styrene acrylate copolymers to be applied in paper coating. Egyptian ground calcium carbonate "GCC" was also investigated as a pigment. The evaluation was concerned with, among others, mechanical properties; porosity and printability. For the first time, the employed base papers for offset printing were recycled brown ones.

Egypt. J. Chem. 59, No. 6 (2016) 
Novel Recycled Brown Paper Coatings

\section{Materials}

\section{Materials and Methods}

Latex ingredients

Laboratory grade styrene (St), butyl acrylate (BuAc), acrylic acid (AA) acrylamide (Am) monomers and potassium persulfate "KPS", supplied by Sigma-Aldrich, Germany, were used as received. The surfactants, namely, Nonyl phenol ethoxylated (NP30), sodium lauryl ether sulphate (SLS), cetyl alcohol and texapon p. (Tex) were purchased from El-Gomhoria Company, Egypt. Ammonium hydroxide and sodium acetate for $\mathrm{pH}$ control and regulation; respectively, were obtained from El-Nasr for Chemical Industries, Egypt.

Base paper types and properties fiber.

Brown paper of basis weight $300 \mathrm{~g} / \mathrm{m}^{2}$, used for coating was $100 \%$ recycled

\section{Pigments}

The pigment used was ground calcium carbonate "GCC" slurry pigment was purchased from Ascom Co., Egypt.

Specifications:

- White powder dispersed in water "slurry dispersion ready to use".

- $\quad 70 \%$ solid content and $70 \%$ of the particles is smaller than $2 \mu \mathrm{m}$.

Binders

1. Commercial latex binder VANCRYL PM 4050 (P) was supplied by VAN Chem. Company, $6^{\text {th }}$ October, Egypt.

2. Prepared binders:

Styrene butyl acrylate lattices with different molar ratios in presence of different emulsifying systems are designated as $\mathrm{C} 1$ to C6whereacrylamide modified copolymers are designated as D1 \& D2 as represented in Table 1.

The number after the binder code denotes to the binder percentage. The solid content of all prepared coating slurry formula was about $60 \%$.

\section{Polymerization technique}

Polymerization procedure

Polymerization was carried out in 500ml 3-necked flask fitted with reflux condenser, thermometer and a mechanical stirrer. The temperatures of homogenization and polymerization were 25 and $80^{\circ} \mathrm{C}$, respectively and nitrogen was purged during the polymerization step.

During the process, the surfactant quantity was divided into two parts, namely, $\mathrm{A}$ and $\mathrm{B}$ with the ratio of $1: 3$ and the process included the following steps: 
1. Part A, containing styrene and butyl acrylate, was emulsified in a little amount of de-ionized water and homogenized for 15-20 min at speed $3500 \mathrm{rpm}$ in order to form pre-emulsion $\mathrm{C}$.

2. $10 \%$ of $\mathrm{C}$ was seeded to the reactor, containing part $\mathrm{B}$; de-ionized water and $\mathrm{pH}$ regulator, for the duration of $15 \mathrm{~min}$ with low speed mechanical agitator $(80 \mathrm{rpm})$ and at $80^{\circ} \mathrm{C}$. The allowed time for micelle formation was an additional $15 \mathrm{~min}$.

3. Acrylic acid and acrylamide monomers were added to the remainder of part C (90\%), under the homogenizer for 5-10 min.

4. Afterward, this acidic emulsion was added to the reactor through dropping funnel in $150 \mathrm{~min}$.

5. In steps $2 \& 4$, a continuous dropping of the initiator solution was performed in the reactor.

6. At the end of addition of all ingredients, polymerization was allowed to continue for additional $2 \mathrm{hr}$ then the reaction, mixture was cooled to $50^{\circ} \mathrm{C}$ and subsequently neutralized with aqueous ammonium hydroxide to reach $\mathrm{pH}$ value of 8 .

Latex formulation

TABLE 1. Formulation of the prepared latexes.

\begin{tabular}{|l|c|c|c|c|c|c|c|c|}
\hline $\begin{array}{l}\text { Components } \\
\text { (wt. \%) }\end{array}$ & C1 & C2 & C3 & C4 & C5 & C6 & D1 & D2 \\
\hline St & 23 & 25 & 27 & 23 & 25 & 27 & 23 & 23 \\
\hline BuAc & 27 & 25 & 23 & 27 & 25 & 23 & 27 & 27 \\
\hline SLS & 1 & 1 & 1 & - & - & - & 1 & - \\
\hline Tex & - & - & - & 1 & 1 & 1 & - & 1 \\
\hline NP30 & - & - & - & 0.2 & 0.2 & 0.2 & - & 0.2 \\
\hline Cetyl alcohol & 0.2 & 0.2 & 0.2 & - & - & - & 0.2 & - \\
\hline
\end{tabular}

KPS $(0.75 \%)$; AA $(4 \%)$; sodium acetate $(0.6 \%)$, temperature $80^{\circ} \mathrm{C}, \mathrm{pH} 8.5$, feed rate $1.38 \mathrm{ml} / \mathrm{min}$, and the initial components content was $50 \%$. In case of D1 and D2, acrylamide was $(0.4 \%)$.

\section{Characterization}

Latex

The prepared copolymers were investigated by the following measurements: dry solid content, viscosity, wet coagulum, particle size and zeta potential.

The particle size and particle size distribution of the prepared polymer samples were defined by dynamic light scattering using Malvern Zetasizernano, UK. The same instrument was used to measure the zeta potential values of the prepared polymers in the range between -200 and $+200 \mathrm{mV}$. The solid content of the prepared polymers was determined gravimetrically at $105^{\circ} \mathrm{C}^{(10)}$.

Coating color formulation

Egypt. J. Chem. 59, No. 6 (2016) 
Novel Recycled Brown Paper Coatings

Table 2 represents formulation of the prepared binders C2, D1 and D2 and commercial binder $\mathrm{P}$ with different using binder ratio $10 \%, 12 \%, 14 \%, 16 \%$ using GCC pigment and other additives and applied using film application for coating of recycled paper.

TABLE 2. Formulations of the prepared and commercial binder using GCC pigment.

\begin{tabular}{|c|c|c|c|c|c|c|c|c|c|c|c|c|c|c|c|c|c|}
\hline \multicolumn{2}{|c|}{ Formula } & $\begin{array}{l}\mathbf{F} \\
\mathbf{1}\end{array}$ & $\begin{array}{l}\mathbf{F} \\
\mathbf{2}\end{array}$ & $\begin{array}{l}\mathbf{F} \\
\mathbf{3}\end{array}$ & $\begin{array}{l}\text { F } \\
4\end{array}$ & $\begin{array}{c}\mathbf{G} \\
\mathbf{1}\end{array}$ & $\begin{array}{c}\mathbf{G} \\
\mathbf{2}\end{array}$ & $\begin{array}{l}\mathbf{G} \\
\mathbf{3}\end{array}$ & $\begin{array}{l}\text { G } \\
4\end{array}$ & $\begin{array}{l}\mathbf{H} \\
\mathbf{1}\end{array}$ & $\begin{array}{l}\mathbf{H} \\
\mathbf{2}\end{array}$ & $\begin{array}{c}\mathbf{H} \\
\mathbf{3}\end{array}$ & $\begin{array}{c}\text { H } \\
4\end{array}$ & I1 & I 2 & I3 & I4 \\
\hline \multirow{4}{*}{ Binder } & $\mathrm{C} 2$ & 10 & - & - & - & 12 & - & - & - & 14 & - & - & - & 16 & - & - & - \\
\hline & D1 & - & 10 & - & - & - & 12 & - & - & - & 14 & - & - & - & 16 & - & - \\
\hline & D2 & - & - & 10 & - & - & - & 12 & - & - & - & 14 & - & - & - & 16 & - \\
\hline & $\mathrm{P}$ & - & - & - & 10 & - & - & - & 12 & - & - & - & 14 & - & - & - & 16 \\
\hline Pigment & $\mathrm{CaCO}_{3}$ & 88 & 88 & 88 & 88 & 86 & 86 & 86 & 86 & 84 & 84 & 84 & 84 & 82 & 82 & 82 & 82 \\
\hline Additives & \multicolumn{17}{|c|}{ Dispersing agent 0.1 , antifoam $0.5, \mathrm{NH}_{4} \mathrm{OH}$ pH control at 8.5. All ingredients weighted in grams. } \\
\hline
\end{tabular}

\section{Coated papers}

Base paper and coated papers properties were determined after conditioning at $25^{\circ} \mathrm{C}$ and $65 \%$ relative humidity for $24 \mathrm{~h}$. All paper properties were evaluated using TAPPI and ISO standard methods.

Water absorbency of paper (Cobb Value) is defined as the amount of water absorbed in a given time by one side of a unit area of paper or board placed horizontally under a head of one centimeter water. This test was performed according to TAPPI T $441-\mathrm{m}-45^{(11)}$ and ASTM D 2045-647 ${ }^{(12)}$.

Air resistance, is the resistance to the passage of air, offered by the paper structure, when a pressure difference exists across the boundaries of the specimen. It is quantified by obtaining the time for a given volume of air to flow though a specimen of given dimensions under a specified pressure, pressure difference, temperature, and relative humidity. This method was used to measure the air resistance of approximately $6.45 \mathrm{~cm}^{2}$ circular area of paper, using a pressure differential of $1.22 \mathrm{kp}$ according to Tappi standard test method T460 om- $02^{(13)}$. The instrument used was W\&L .E Gurley densometer Troy, N.Y .USA. Gloss describes the mirror-like property of a coated surface and is defined as the percentage of the light that is reflected from the surface at an angle equal to the angle of incidence, in comparison with a standard surface. 
Paper gloss was measured by micro gloss meter at angle $75^{\circ}$. The test was performed according to the TAPPI T480, OM- $92^{(14)}$.

Tensile strength can be defined as the maximum tensile stress developed in a test specimen before rupture under prescribed conditions. The tensile tester, model PAP-2065, conformed to international standard TAPPI T 494-cm-92 ${ }^{(15)}$ was used.

Crush tester measures the maximum compressive force that a test piece will sustain without being crushed, the test piece being in the form of a cylinder, standing in one end, and the force being applied to the other end under specified conditions. The apparatus conforms to international standard TAPPI T 822-om-93.

Burst is the resistance of paper to puncture. Bursting pressure is applied by rubber diaphragm at controlled increasing rate across $30.5 \mathrm{~mm}$ paper diameter. Bursting strength tester is intended for measuring the bursting strength of strong Kraft paper and board by submitting it to an increasing uniform hydraulic pressure. This instrument is reliable and conforms to the international standard BS 3137, ISO 2758, TAPPI T $403^{(16)}$ OS-76 and TAPPI T OM-85.

\section{Printing process}

Coated paper was printed with IGT printability tester according to ISO 2834-1(2006) ${ }^{(17)}$. Test strips were of length $315 \mathrm{~mm}$ and width $30 \mathrm{~mm}$. An offset ink supplied by Paint and Chemical Industries Company "Pachin", Egypt, was used.

A sufficient amount of ink was applied to the IGT inking unit and distributed uniformly on different rolls of the inking unit. The printing disc was cleaned after printing each strip using a solvent (cyclohexanone). For each type of paper sheets, a series of strips was printed with the same ink. The prints were allowed to air-dry over night. Various reflectance values on the test strips were measured using densitometer in order to evaluate print density and print gloss. The reflectance was measured by Spectroeye apparatus, X.rite Company, USA. An average of five measurements was recorded for each printed strip.

The obtained data in this work represents the average of 10 readings. The average, the standard deviation, and the relative error were computed using standard statistics.

\section{Results and Discussion}

\section{Characterization of the prepared latexes}

The following Table 3 represents the measured physical properties of assynthesized emulsions and the commercial polymer (P). Stability of lattices was carried out in an accelerating test for periods six month and three years. 
Novel Recycled Brown Paper Coatings

TABLE 3. Physical properties of the prepared emulsions and the commercial polymer $(\mathbf{P})$.

\begin{tabular}{|c|c|c|c|c|c|c|c|c|c|}
\hline $\begin{array}{ll}\text { Property } & \text { Run } \\
\end{array}$ & C1 & $\mathrm{C} 2$ & C3 & $\mathrm{C} 4$ & C5 & C6 & D1 & D2 & $\mathbf{P}$ \\
\hline Solid content $(\%)$ & 46.8 & 48.9 & 47 & 46.8 & 47.9 & 48.8 & 48.6 & 48.8 & 50 \\
\hline $\begin{array}{l}\text { Wet coagulum } 100 \\
\text { mesh, }(\mathrm{g} / \mathrm{l})\end{array}$ & 1.7 & 0.8 & 0.8 & 1.2 & 0.8 & 1.3 & 0.6 & 0.8 & - \\
\hline Particle size $(\mathrm{nm})$ & 99 & 98 & 90 & 115 & 120 & 229 & 80 & 100 & 95 \\
\hline Viscosity (cP) & 295 & 260 & 164 & 159 & 140 & 180 & 400 & 350 & 500 \\
\hline Zeta potential $(\mathrm{mV})$ & -46 & -42 & -67 & -32 & -35 & -46 & -69 & -54 & -55 \\
\hline $\begin{array}{l}\text { Storage stability at } \\
25^{\circ} \mathrm{C} \text { for } 3 \text { years } \\
\begin{array}{l}\text { (shelf-life of the } \\
\text { product) }\end{array}\end{array}$ & pass & pass & pass & pass & pass & pass & pass & pass & pass \\
\hline $\begin{array}{l}\text { Storage stability } 37^{\circ} \mathrm{C} \\
\text { for } 6 \text { months }\end{array}$ & pass & pass & pass & pass & pass & pass & pass & pass & pass \\
\hline
\end{tabular}

The solid content had somewhat constant value which can be attributed to the complete polymerization of the monomers that had initial constant molar ratio.

The solid content and coagulum of the prepared copolymers were determined gravimetrically and recorded in Table 3, the low coagulum values may indicate that the primary particles were well protected by surfactant molecules from the beginning of polymerization. Particle aggregation, if any, was almost restricted.

It is worth mentioning that high solid content $50 \%$ and low coagulum were the main request in production of styrene/butyl acrylate carboxylic acid emulsion on a large scale for paper coating applications ${ }^{(18)}$.

Particle size directly has an impact on the physical stability of emulsions, i.e. the smaller the dispersed particles, the more stable the system is. Consequently, the particles must be small to permit a film formation around the droplets in the dispersed phase. Reduced particle size lets more particles to be distributed on the boundary, yielding a more stable emulsion ${ }^{(19)}$.

The high solid content and the low coagulum together with the small particle size prove the stability prepared polymers.

It is obvious that $\mathrm{C} 1$ had high viscosity and low particle size, but $\mathrm{C} 2$ is the more stable "high -ve value of zeta potential". The presence of acrylic acid enhanced viscosity due to hydrogen bonding ${ }^{(20)}$.The particle size of the prepared latexes was small and the viscosity of the prepared lattices was proportionally increased with decreasing particle size which in turn decreased by increasing the surfactant concentration. The prepared lattices had narrow particle size 
distribution (164-295) $\mathrm{nm}$ in case of using system of surfactant consist of SLS \& cetyl alcohol surfactant system, while it was (140-159) nm in case of using texapon \& NP30 surfactant system.

The results of this study help to predict the stability behavior of emulsions prepared by analyzing their zeta potential.

Normally, emulsions that have $\xi$ zeta potentials higher than $+30 \mathrm{mV}$ or lower than $-30 \mathrm{mV}$ are considered stable ${ }^{(21)}$. Therefore, it can be considered that all prepared emulsions had good stability.

Fortunately, increasing zeta potential is a driving force to prevent particles from stacking; leading to the creation of nano scale stable particles

The number of micelles increased with the increasing surfactant content, there for more sites for polymerization occurred and smaller particle size of latexes formed. The surfactant was useful to control the particle size of latexes ${ }^{(22)}$.

Increasing of styrene content enhanced the stability with respect to the measured zeta potential.

The values obtained by measuring the zeta potential of the prepared latexes help to predict the stability of the prepared emulsion. There is a direct relationship between zeta potential and emulsion concentration. The values of zeta potential in range (-46: -35$)$ meaning that the prepared emulsion latexes are stable and this can be proved by low coagulum values of emulsion latex.

Stability testing is an integral part of emulsion development work. The emulsion formulator is generally concerned with understanding the effects of storage and shipping conditions on shelf-life which may include extremes of temperatures and exposure to sunlight, vibration and humidity. Accordingly, formulations were stored under standardized test conditions and carefully examined at periodic intervals in compliance with applicable ICH guidelines. Fortunately, the prepared binders had the same shelf stability compared to the commercial one exploring no coagulation

\section{Coated papers characterization}

Water absorption measurements (Cobb 60 values)

The water absorption capacity of coated paper, well-ordered by ratio of polymer and the type of pigment in coating recipe, indicates the paper resistance to water. Figure 1 shows $\mathrm{Cobb}_{60}$ value $\left(\mathrm{g} / \mathrm{m}^{2}\right)$ for different polymer content. The blank samples were coated with the commercial binder at different pigment ratio.

The absorptivity of base paper was clearly reduced by the applied coatings and this coincides with the observation of Wang et al. ${ }^{(23)}$. 
Novel Recycled Brown Paper Coatings

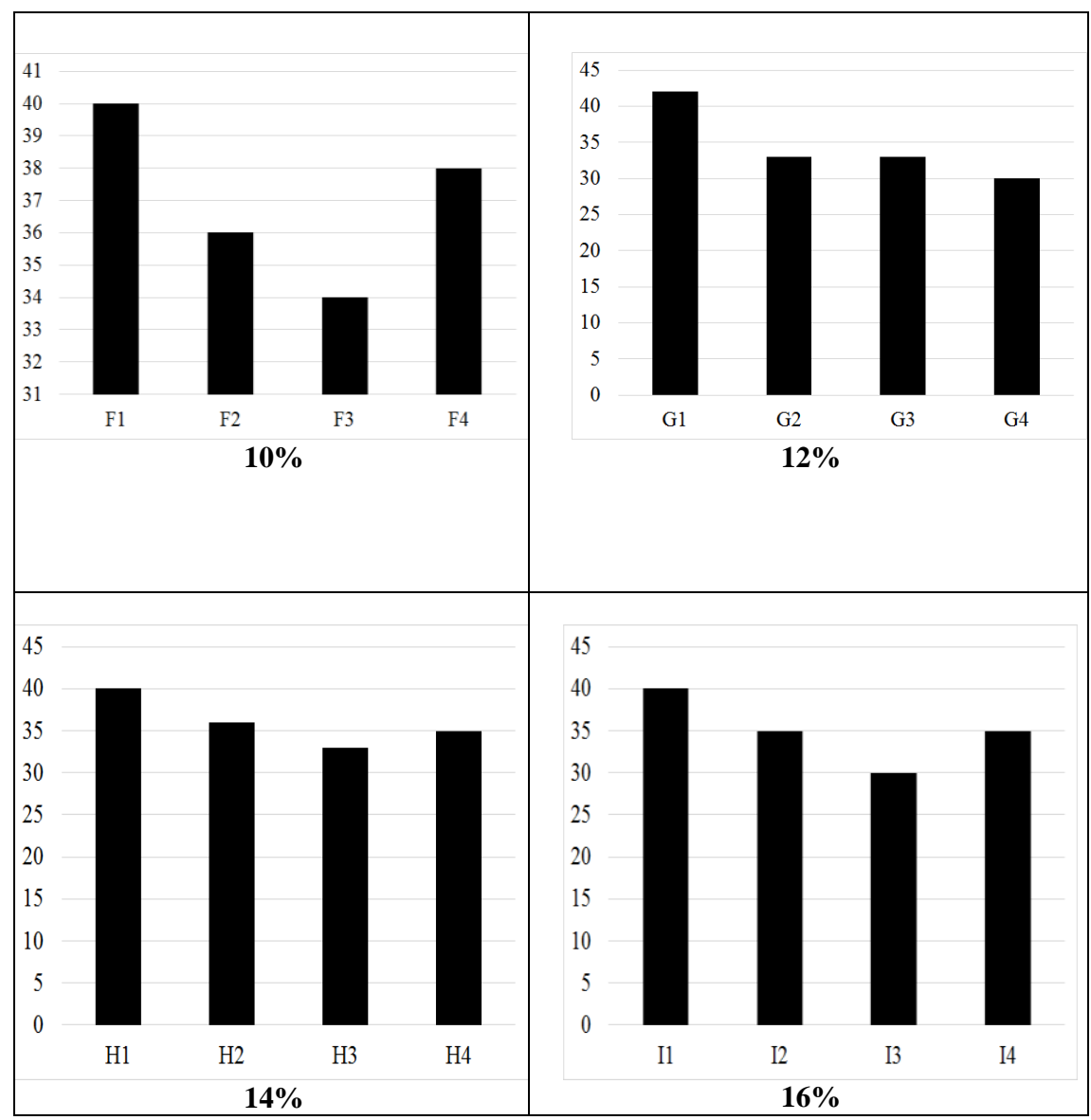

Fig.1. Cobb60 values of coated paper using formulations based on $10 \%, 12 \%, 14 \%, 16 \%$ binder ratio of prepared and commercial binder.

Also, it can be noted that lowest Cobb $_{60}$ values, (in range of $30 \mathrm{~g} / \mathrm{m}^{2}$ ), were obtained for papers coated with the highest polymer concentration. This is due to the hydrophobic nature of polymers used relative to the hydrophilic nature of paper. To conclude, the hydrophobicity can be considered a first barrier against water uptake.

To conclude, the prepared latex polymer (D2) had better resistance to water than the commercial one. This property was achieved at $16 \%$ polymer. These promising results can tightly be correlated with print quality, printability and productivity as it can be seen in the following sections. Moreover, from the economical point of view, the ink consumption can be reduced by applying our formula relative to the commercial one and last of all, low viscous ink can be applied. It is a matter of cost saving in printing industry. 
Porosity (air resistance of paper)

Generally, coating the base substrate reduces the air permeability which can improve the coating coverage of the pre-coated paper, especially at low coat weights ${ }^{(24)}$. Figure 2 represents the air permeability $(\mathrm{ml} / \mathrm{min}) /$ area of 1.0 (standard) square inch for coated paper coated with $(\mathrm{F}),(\mathrm{G}),(\mathrm{H})$ and $(\mathrm{I})$ formulations.

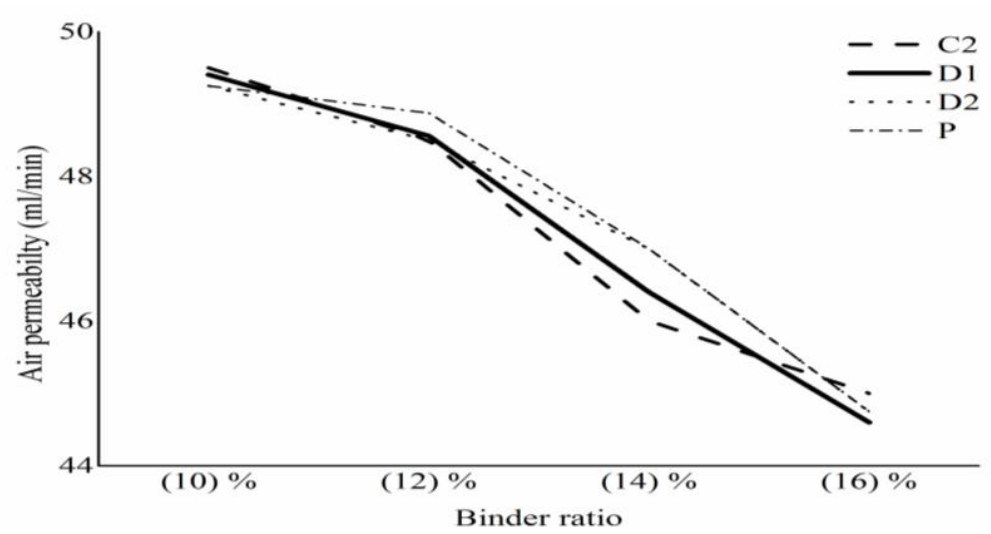

Fig. 2. Porosity of coated paper using different formulation of C2, D1, D2 and commercial binder.

The air permeability is strongly dependent on pigment type. Usage of GCC made many surface pores visible on the coating layer.

The comparable air permeability values with respect to the blank suggest that the prepared latexes had a talented economic value for printing as it has just been observed for $\mathrm{Cobb}_{60}$ values.

\section{Gloss measurements}

The top layer changes the chemical and morphological surface features and determines the final surface properties such as water resistance, compatibility, print quality and optical appearance. Gloss is one of the basic surface characteristics as it strongly affects the visual perception ${ }^{(25)}$.

Figure 3 represents the specular gloss values at $75^{\circ} \mathrm{C}$ for samples coated with binders C2; D1 and D2 compared with commercial binder (P) at different concentrations.

At all binder ratios and types, the gloss of coated papers was higher than uncoated (base) paper. Thus the improvement was 100\%. D1 gave the highest gloss value in case of $10 \%$; this may be due to the used emulsifier system and acrylamide modification. All the prepared binders and commercial binder gave somewhat same gloss value.

Egypt. J. Chem. 59, No. 6 (2016) 
Novel Recycled Brown Paper Coatings

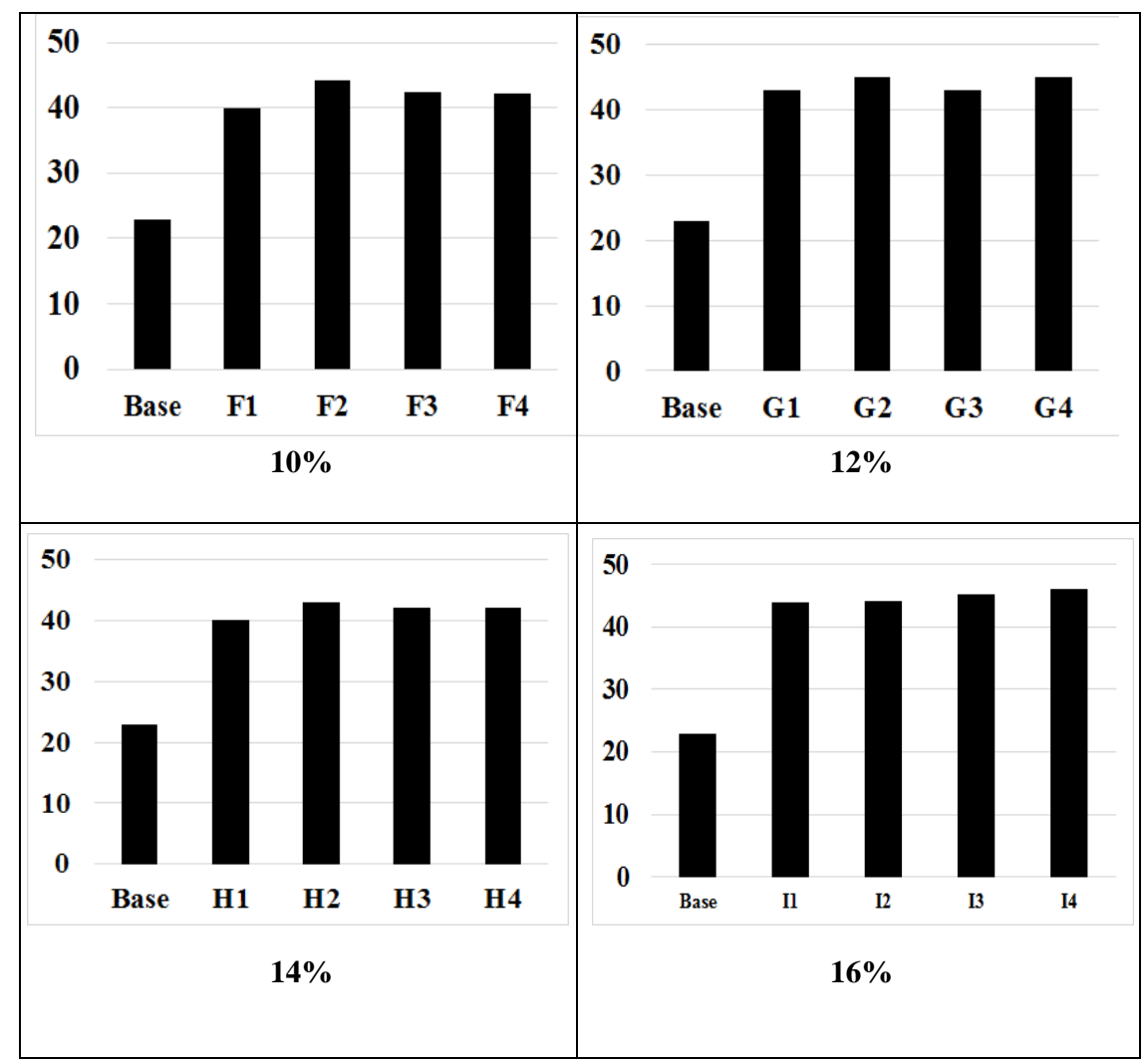

Fig. 3. Gloss of coated paper using formulations based on $10 \%, 12 \%, 14 \%, 16 \%$ binder ratio compared with B "base paper".

The gloss of $\mathrm{C} 2$ formulations with higher styrene content had approximately the same values compared with other corresponding formula although it was postulated that the gloss may depend inversely on the styrene content in the styrene-maleic anhydride copolymer coatings ${ }^{(26)}$.

These promising results could pave the road for our formula to be applied in the coating process.

Mechanical properties of coated paper

High mechanical properties are usually required to maintain packaging integrity during shipping, handling and storage.

During this study, three tests were carried out to assist the mechanical properties of coated paper, namely, tensile strength, ring crush and burst strength tests. 
Tensile strength is dependent on the strength and length of fibers, especially the inter- fiber bonding strength ${ }^{(27)}$.

It is worth to mention that ring crush test has a strong historical footing and has been the default test for evaluating paper compression strength for the paper ${ }^{(28)}$.

Burst testing is the method used to estimate the usability and behavior of paper when perpendicular forces act on the surface. It can indicate the resistance to rupture of paper materials ${ }^{(29)}$.The burst strength is highly related to the strength of fiber bonding in paper making. This is due to the penetration of coating binder into the fibers arrangement and the resemblance of the chemical structure between binder and cellulose fibers which has higher compatibility ${ }^{(30)}$.

The ring crush correlated with compressive deformation, where the burst test associated with breakdown fibers.

Figures 4, 5 and 6 represent the above mentioned mechanical parameters for coated brown substrates.

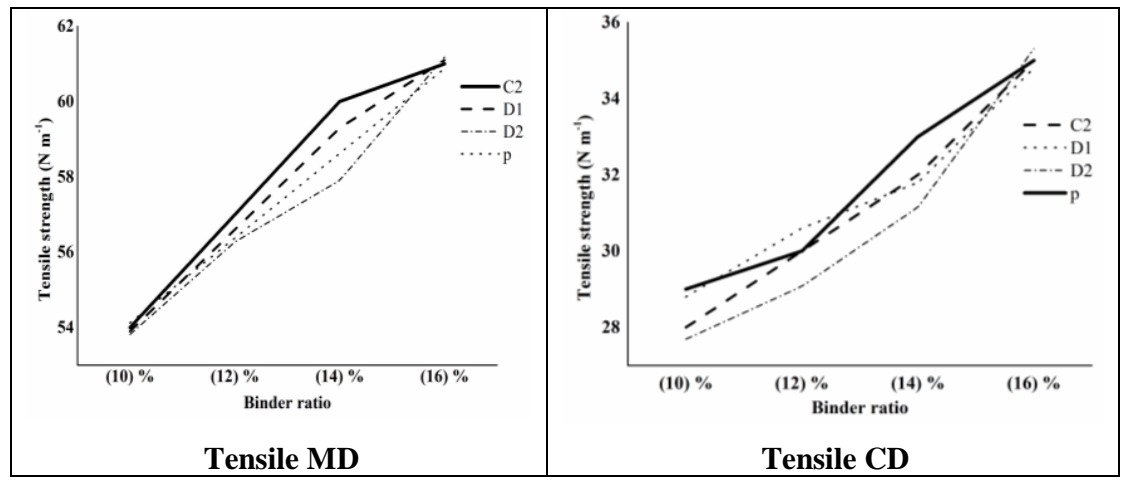

Fig. 4. Machine direction (MD) and cross direction (CD) tensile strength of coated paper.

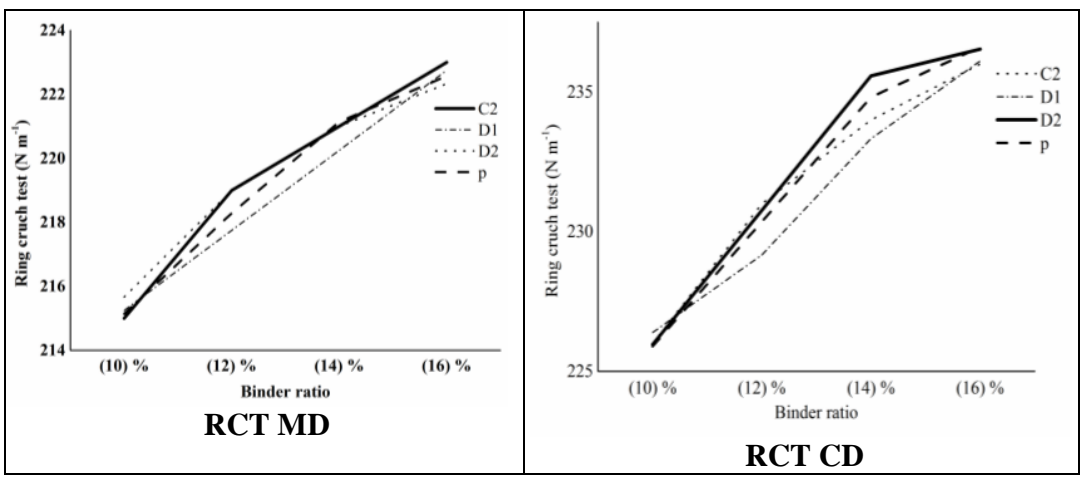

Fig. 5. Machine direction (MD) and cross direction (CD) ring crush of coated paper.

Egypt. J. Chem. 59, No. 6 (2016) 


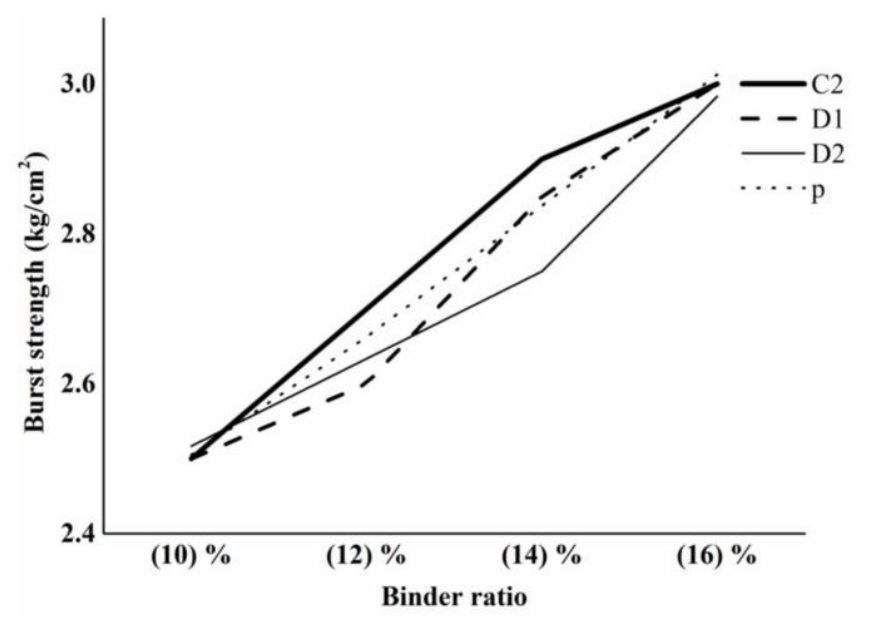

Fig. 6.Burst strength of coated paper.

MD tensile strength, as shown in Fig. 4, the more binder ratio, the more tensile strength is. C2 and D1 gave excellent results compared with D2 and commercial binder $\mathrm{P}$ in $\mathrm{MD}$, however, $\mathrm{C} 2$ gave the highest tensile strength in $\mathrm{CD}$ compared with the synthesized polymers. The improvement ratio $\sim 5-8 \%$ in MD in tensile strength and $\sim 20-30 \%$ in CD in tensile strength compared with that of the uncoated paper.

On behave of ring crush test in MD and CD, Fig. 5 shows that:

1. Increasing binder ratio led to increasing the RCT values.

2. Formulations using $\mathrm{C} 2$ gave the highest MD RCT.

3. Formulations using D2 gave the highest CD RCT.

With respect to bursting strength values shown in Fig. 6, the binder ratio was in a direct relationship with the burst strength.

With each sample was performed in the machine and cross direction tensile strength. The machine direction tensile strength is notably higher because of the formation of fibers and the fiber bonds have more strength in machine direction.

Results showed that tensile strength has the best correlation with all strength properties of paper, i.e., bursting strength and ring crush. The higher the tensile strength, the higher will be the resistance against machine breaks. Furthermore coated paper proved to be the type of paper grade that has the 
strongest resistance against the failure during the processed at coating machine or printed through printing machine ${ }^{(31)}$.

These results are in agreement with those obtained by Zakaria et al. ${ }^{(30)}$ who utilized chitosan as paper coating. In our case, the acrylic acid has occupied the pores and some of them adhered only on the surface. This may be due to the chemical similarities between cellulose and acrylic acid which enhanced the strength of fiber matrixes via hydrogen bonding.

Printability of coated paper "Evaluation of print quality" (gloss and density)

In the coating process and in later printing stage, the size and shape of the pigment particles is very important. The gloss of a coated sheet is correlated with the fibers coverage caused by the coating, particularly on the tops of the fibers, and on the roughness of the coating. The latter has two most important components which unite to create the surface topography that influences gloss. Firstly, the pigment particles donate to the small-scale micro-roughness by asset of their size and shape, and the packing method on the paper surface. Secondly, the base-paper fibers lying below the coating affect the surface roughness, particularly at low coat weight, due to absence of complete matching between the small amount of coating and the size and shape of the fibers ${ }^{(32)}$.

Print quality is expressed by sharpness of image, color, tone, gloss, print density and the uniformity of these properties ${ }^{(33)}$.

The amount of specular gloss is based on the surface structure and porosity of substrate while the print density is symbolic of a higher thickness of ink layer, which is itself a consequence of the wider coating network besides the stronger bonding between paper and ink ${ }^{(34)}$.

Figures 7 and 8 illustrate the print quality of coating formulas utilizing the prepared and commercial binder. Middle quality sheet fed offset ink red was used with average gloss $40-50$ for the printing process while its print density was of 1.5-1.8. Many points can be highlighted as follows:

- Print gloss and print density were highly and directly correlated. This may be explained as low print gloss is an evident of a rough print surface and this indicates that the print density is also low, leading to both image and color reproduction poorness ${ }^{(7)}$.

- Increasing the binder ratio enhanced the gloss values.

- The print density ranged from 2.0 to 2.5 compared with 1.5 and 2 which were reported for the uncoated and coated papers, respectively ${ }^{(35)}$.

- The maximum gloss value (33) was obtained for $14 \% \mathrm{C} 2$.

- The maximum print density values (2.4) were obtained for $16 \% \mathrm{C} 2$ and D2.

Egypt. J. Chem. 59, No. 6 (2016) 
Novel Recycled Brown Paper Coatings

- Coated recycled brown base paper gave promising results with respect to print quality; taking into consideration that for the printing quality purposes, offset printing is usually performed on coated virgin pulp white base paper.

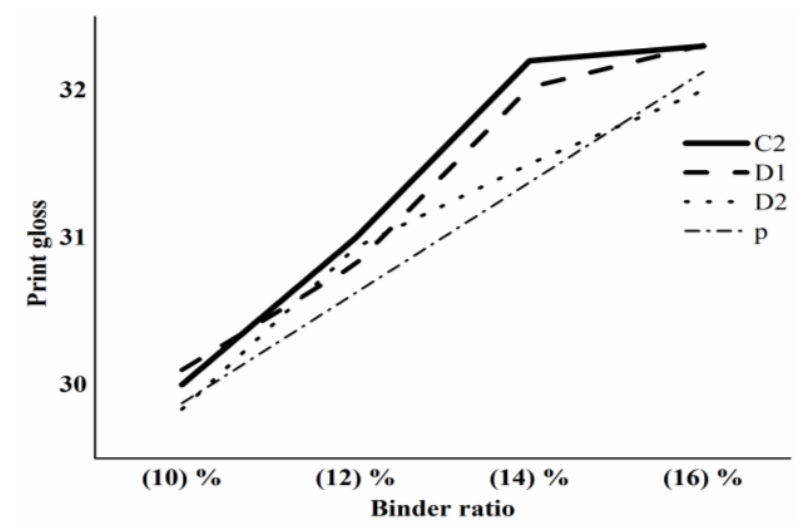

Fig.7. Print gloss of coated paper.

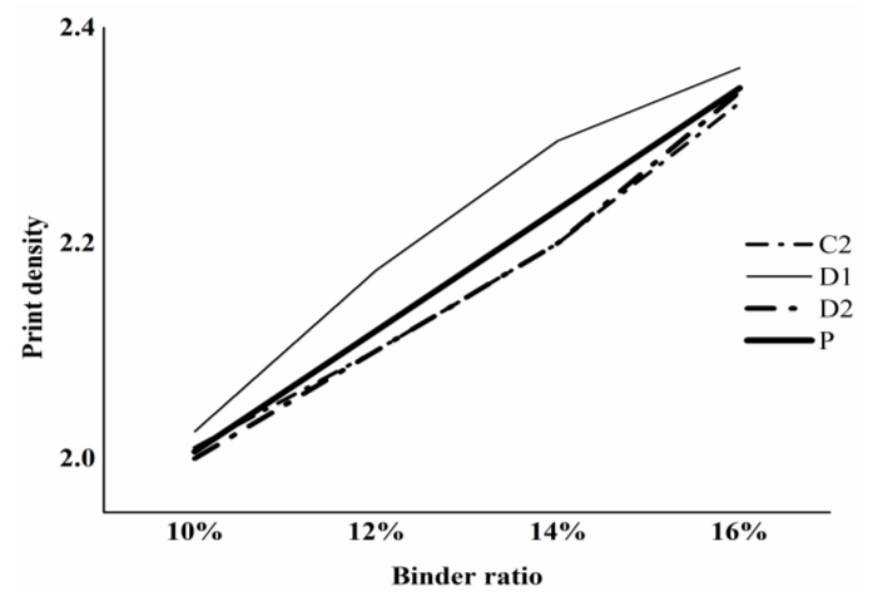

Fig. 8. Print density of coated paper.

\section{Conclusion}

The water absorption of coated papers was $30 \mathrm{gm} / \mathrm{m}^{2}$ compared with $35 \mathrm{gm} / \mathrm{m}^{2}$ for the commercial one. This means that ink consumption can be decreased by $\approx 30 \%$ in concert with the possibility of usage of low viscous ink. Gloss of coated papers was upgraded to more than double that of base ones. Air flow meter values indicated that paper surface porosity decreased considerably 
when the paper was coated with prepared styrene butyl acrylate, due to forming of a continuous coating layer. The burst strength; ring crush and the tensile strength for the coated papers were simultaneously improved compared with the commercial ones. The printability of coated papers was as well superior to the commercial one; this can evidently reduce the economic cost of the printing process.

\section{References}

1. Fardim, P. and Holmbom, B., ToF-SIMS imaging: a valuable chemical microscopy technique for paper and paper coatings, Elsevier Appl. Surf. Sci. 249, 393 - 407 (2005).

2. Hult, E.L., Lotti, M. and Lenes, M., Efficient approach to high barrier packaging using microfibrillar cellulose and shellac, Cellulose, 15, 575-586 (2010).

3. Wu, Yu Ju, The effect of substrate properties on print attributes for Gravure Printing - from proof to press, PhD Thesis, Western Michigan University Kalamazoo, Michigan Dissertations Paper 823(2008).

4. Wang, Sh., Mahlberg, Riitta, Nikkola, J., Mannila, J., Jämsä, S., Ritschkoff, Anne-Christine and Peltonen, J., Surface characteristics and wetting properties of sol-gel coated base paper, Surface and Interface Analysis, 44(5), 539-547 (2012).

5. Bollström, R., Tobjörk, D., Dolietis, P., Salminen, P., Preston, J., Österbacka, R. and Toivakka, M., Printability of functional inks on multilayer curtain coated paper, Chemical Engineering and Processing, 68, 13-20 (2013).

6. Herbert, H., Werner, K., Auhorn, W. J. and Martin, T., "Handbook of Paper and Board", Coating of Paper and Board, pp. 332-382. Werner, Wiley-VCH. Germany (2005).

7. Sinan, S., Emre, D. and Fleming, P.D., Binder effect on the creasability of pigment coated paper board . Asian Journal of Chemistry, 23(3), 1193-1197 (2011).

8. Aydemir, C., Ozomay, Z., Karademir, A. and Kandırmaz, E.A., Effect of matte coating on the paper surface and print density. Sci. Eng. Compos. Mater. 20(2), 141145(2013).

9. Despond, S., Epuche, E., Cartier, N. and Domard, A., Barrier properties of paper-chitosan and paper-chitosan-carnauba wax film, J. Appl. Polym. Sci. 98, 704$710(2005)$

10. ASTM D 4209-07, 2013.

11. TAPPI T 441-m-45.

12. ASTM D 2045-647.

13. TAPPI T 460 om -02 .

14. TAPPI T 480, om $\mathbf{- 9 2}$ stander.

Egypt. J. Chem. 59, No. 6 (2016) 


\section{TAPPI T 494-cm-92.}

\section{TAPPI T 403.}

17. ISO 2834-1(2006).

18. Hussain, A.I and Nasr, H.E, The role of carboxylic acid on the characterization and evaluation seed emulsion of styrene/butyl acrylate copolymers lattices as paint, Nature and Science, 8 (8), 94-103 (2010).

19. Tadros, Th. F., "Emulsion Formation and Stability", $1^{\text {st }}$ ed., Wiley-VCH Verlag GmbH \& Co. KGaA. Published 2013 by Wiley-VCH Verlag GmbH \& Co. KGaA, (2013).

20. Chen, Nan-xi and Zhang, Jun-h., The role of hydrogen bonding interaction in poly (vinyl alcohol) / poly (acrylic acid) blending solutions and their films, Chinese Journal of Polymer Science, 28(6), 903-911 (2010).

21. Cangialosi, D., Alegría, A. and Colmenero, J., Effect of nanostructure on the thermal glass transition and physical aging in polymer materials, Progress in Polymer Science, 54(55), 128-147 (2016).

22. Ismail, H., Ahmad, Z. and Yew, F. W., Effect of monomer composition on adhesive performance for waterborne acrylic pressure-sensitive adhesives. Journal of Physical Science, 22(2), 51-63 (2011).

23. Wang, S., Mahlberg, R., Nikkola, J. and Peltonen, J., Surface characteristics and wetting properties of sol-gel coated base paper, Surface and Interface Analysis, 44(5), 539-547 (2012).

24. Forsstrom, U., Dickson, R. and Gron, J. Coating coverage and structure of wood free paper pre coated with the film press. Wochenblatt Fur Papierfabrikation, 128(14-15), 985-992(2000).

25. Pieter, S. Jürgen Van Erps and Hugo Thienpont, Specular gloss versus surface topography for oil - filled nanoparticles coating on paper, Color Research and Application, 41(6), 596-610 (2015)

26. Samyn, P., Deconinck, M., Schoukens, G., Stanssens, D., Vonck, L. and Van den Abbeele, H., Modification of paper and paperboard surfaces with a nano structured polymer coating. Progress in Organic Coating, 69, 442-454 (2010).

27. Vainio, A. and Paulapuro, H., Interfiber bonding and fiber segment activation in paper, Bio Resources, 2(3), 442-458 (2007).

28. Frank, B., Revisting of paper strength measurements for estimating combined board strength, TAppi, Journal, 6 (9), 10-17 (2007). 
29. Rhim, J. H., Lee, J. H. and Hory, S. I., Water resistance and mechanical properties of biopolymer alginate and say protein, Coated paper board. LWT-food Sciences Technology, 39 (7), 806-813 (2006).

30. Zakaria, S., Chia, Ch. H., Ahmad, W. H. W. and Hatika, K., Mechanical and antibacterial properties of paper coated with chitosan. Sains Malasiana, 44 (6), 905$911(2015)$.

31. Tracton, A. A., "Coatings Technology: Fundamentals, Testing, and Processing Techniques". Chapter 25; by Taylor \& Francis Group, LLC .New York (2007).

32. Adams, J.M., Particle size and shape effects in materials science: examples from polymer and paper systems. Clay Minerals, 28, 509-530(1993).

33. Gigac, J., Stankovská, M. and Kasajová, M., Interactions between offset papers and liquids. Wood Research, 56(3), 363-370 (2011)

34. Kasmani, J.E., Mahdavi, S., Alizadeh, A., Nemati, M. and Samriha, A. Physical properties and printability characteristics of mechanical printing paper with LWC. Bio Resources, 8(3), 3646-3656(2013).

35. Tripathi, P., Joyce, M., Lee, D.I., Fleming, P.D. and Sugihara, M., Comparison of the surface and print quality of curtain and blade coated papers. Swansea Printing Technology Ltd, TAGA J., 3, 203-213 (2007). 
Novel Recycled Brown Paper Coatings

دهانات جديده للورق البنى المعاد تدويره

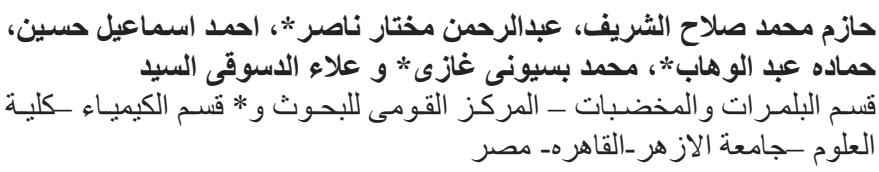

تستخدم مستحلبات الاستيرين اكريللك كو بوليمر حاليا بشكل كبير فى نطبيق

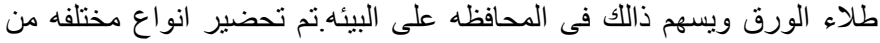

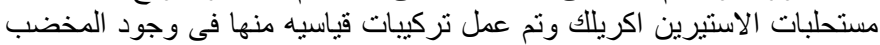

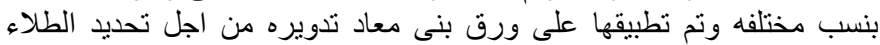

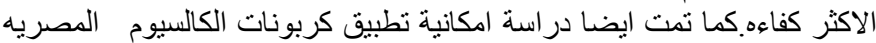

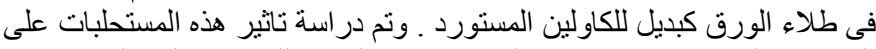

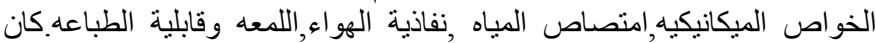

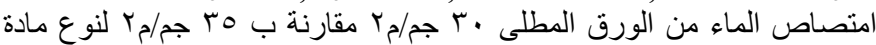

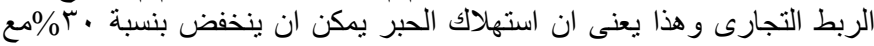

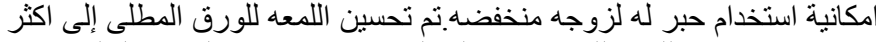

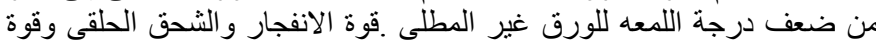

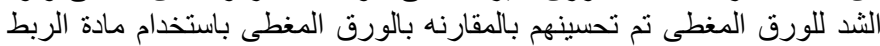

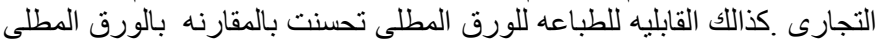

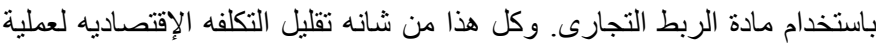
الطباعه 